\title{
A constitucionalização do direito de autor e as potencialidades da internet para a difusão da cultura
}

\section{The constitutionalization of copyright and the potential of internet to cultural diffusion}

\author{
Rosane Leal da Silva* \\ Letícia Almeida de la Rue ${ }^{* *}$
}

\section{Resumo}

O presente trabalho objetiva analisar a influência da constitucionalização do direito no campo do direito de autor, bem como verificar em que medida a sociedade informacional tem o potencial de contribuir com a concretização da função social desse direito, promovendo o acesso à cultura. Na primeira parte, é abordada a constitucionalização do direito privado e de que forma esse fenômeno impôs a revisão do tratamento jurídico do direito de autor. Na segunda parte, verifica-se como se dá o conflito entre direito de autor e direito à cultura no contexto da sociedade informacional, analisando-se as potencialidades que a internet oferece para a difusão de bens culturais. Para tratar do tema, elegeu-se o método de abordagem dialético, tendo em vista as contradições existentes entre esses interesses em colisão. Constatou-se que, apesar do meio digital contribuir para a concretização do direito constitucional de acesso à cultura, uma parte do conteúdo disponível on-line é protegido pela Lei de Direitos Autorais pátria, caracterizando, assim, violação ao direito do titular sobre a obra. Nesse sentido, defende-se a necessidade de uma adaptação da lei, uma vez que o caráter patrimonial e individualista do direito de autor não

Mestrado em Integração Latino - Americana pela Universidade Federal de Santa Maria (2000) e doutorado pela Universidade Federal de Santa Catarina, na área de concentração Direito, Estado e Sociedade, com pesquisa sobre criança e adolescente na sociedade informacional (2009). É professora adjunta da Universidade Federal de Santa Maria. Santa Maria - RS - Brasil. Email: rolealdasilva@gmail.com

* Mestranda do Programa de Pós-graduação em Direito da Universidade Federal de Santa Maria (UFSM), Área de concentração: Direitos Emergentes da Sociedade Global, Linha de Pesquisa: Direitos na Sociedade em Rede. Bolsista Capes. Santa Maria - RS - Brasil. Email:leticiarue@ gmail.com 
encontra mais respaldo na atualidade, devendo esse direito ser pensando em consonância com os valores e princípios irradiados pela Constituição Federal.

Palavras-chave: Constitucionalização do direito privado. Direito de autor. Função social. Sociedade informacional. Internet.

\section{Abstract}

The present work aims to analyze the influence of making the law constitutional, regarding copyright, as well as to verify how much the informational society contributes to ratify the social role of this law, fostering the access to culture. In the first part, it was approached the private law made constitutional and the way this has imposed a revision in the copyright's juridical treatment. In the second part, it was verified the way copyright conflicts with the right to access culture in the informational society, analyzing the internet potential to disseminate cultural assets. It was chosen the dialectic approach method to address this theme due to the contradictions between these shocking interests. It was possible to see that despite the digital environment contributing to confirm the constitutional right to access culture, most of the content available on internet is protected by the country's Copyright Law, characterizing thus violation to the author's copyright on their work. Accordingly, we are for the need of modifying the law, since the property and individual character of the copyright does not match to reality, something that should be thought according to the values and principles stated on the Federal Constitution.

Keywords: Making private law constitutional. Copyright. Social function. Informational society. Internet.

\section{Introdução}

O fenômeno da constitucionalização do direito privado, ocorrido no Brasil principalmente a partir da última década do século $X X$, trouxe sua influência para o campo do direito de autor, o qual sempre teve como essência a ideia de que a titularidade do autor sobre sua obra era absoluta, não podendo ser condicionada em razão de interesses públicos. No entanto, com a virada axiológica pela qual passou o direito 
privado, o direito de autor também sofreu modificações, porquanto se percebeu que este possui uma função social a cumprir, relacionada com o desenvolvimento econômico, cultural e tecnológico de uma sociedade, na medida em que, em nome do interesse comum, devem ser impostos limites à titularidade absoluta do criador sobre a obra.

$\mathrm{Na}$ sociedade informacional, verifica-se o potencial da internet na difusão do conhecimento, em consonância com a função social do direito de autor. No entanto, uma parte do conteúdo divulgado online está em desacordo com a Lei de Direitos Autorais (LDA) pátria, caracterizando violações ao direito do titular sobre a obra. Assim, com o desenvolvimento da internet, o conflito já existente entre o direito à cultura e o direito de autor, ambos assegurados constitucionalmente, acentua-se. É nessa perspectiva que se torna cada vez mais necessário buscar um ponto de equilíbrio entre esses dois direitos fundamentais.

Assim sendo, este trabalho tem o objetivo de analisar a influência da constitucionalização do direito no campo do direito de autor, o que coloca em evidência as tensões entre os interesses do criador da obra e o direito ao acesso à cultura e educação, de escopo social. Para dar conta dessa temática, elegeu-se o método de abordagem dialético, empregado para destacar as contradições existentes entre esses interesses em colisão. Como método de procedimento, foi utilizada uma combinação dos métodos histórico e monográfico. O primeiro foi usado para a análise da evolução dos institutos jurídicos que envolvem o tema, em conjunto com a técnica de pesquisa bibliográfica. Já o segundo foi empregado para exame dos dispositivos referentes à limitação dos direitos de autor na revisão da atual LDA.

À luz dessa metodologia, o artigo foi dividido em duas seções: na primeira parte, é abordada a constitucionalização do direito privado e seus impactos sobre o direito de autor; na segunda parte, verifica-se como se dá o conflito entre direito de autor e direito à cultura no contexto da sociedade informacional, analisando-se as potencialidades que a internet oferece para a difusão de bens culturais. 


\section{Breves apontamentos sobre a constitucionalização do direito privado}

O direito, tradicionalmente separado em público e privado, experimentou uma releitura nos últimos anos do século $X X$, sobretudo após o advento da Constituição Federal de 1988, cujos princípios e valores impuseram uma nova compreensão do fenômeno jurídico, à luz de uma sociedade plural e democrática. Inaugurou-se, pois, um ciclo fértil de estudos e debates sobre a funcionalização dos institutos jurídicos, trazendo para a ordem do dia o tema da constitucionalização do direito privado.

Barroso (2010) leciona que a ideia de constitucionalização do direito está associada a um efeito expansivo das normas constitucionais, cujo conteúdo material e axiológico passa a irradiar, com força normativa, por todo o sistema jurídico. A aproximação entre constitucionalismo e democracia, a força normativa da Constituição e a difusão da jurisdição constitucional são elementos de passagem para o modelo de constitucionalização do direito, o qual, de acordo com o autor, teve origem na Alemanha, quando o Tribunal Constitucional Federal assentou que os direitos fundamentais, além de possuírem uma dimensão subjetiva de proteção a situações individuais, desempenhavam também a função de instituir uma ordem objetiva de valores, a ser observada tanto pelo Estado quanto pela sociedade. Assim, as normas constitucionais passaram a condicionar a interpretação de todos os ramos do direito, público ou privado, e a vincular os Poderes estatais.

Neste contexto, afirma Barroso (2010) que o sistema jurídico se desloca do seu velho eixo - o direito civil, que exerceu, por muito tempo, o papel de um direito geral, conferindo certa unidade dogmática ao ordenamento - para o direito constitucional.

No Brasil, a passagem da Constituição para o centro do sistema jurídico se deu com a redemocratização, por ocasião da promulgação da Constituição de 1988. A partir de então, a Carta Magna passou a desfrutar, ao lado da supremacia formal, da supremacia material, 
exibindo força normativa e funcionando não apenas como parâmetro de validade para a ordem infraconstitucional, mas também como vetor de interpretação para as demais normas do sistema. A ordem jurídica passou a ser lida e apreendida sob a lente da Constituição, buscando a realização dos valores nela consagrados (BARROSO, 2008).

Lôbo (1999) leciona que, ao longo de sua história, o direito civil sempre foi identificado como o locus normativo privilegiado do indivíduo, totalmente distante do direito constitucional. Os códigos civis tiveram como paradigma o cidadão dotado de patrimônio, e as primeiras constituições nada regulavam sobre as relações privadas. E não poderia ser diferente, pois se sabe que o Código Civil de 1916 teve grande influência do liberalismo, para o qual a realização da pessoa humana estava ligada à propriedade, ao patrimônio e ao domínio dos bens.

Para Barroso (2010), a relação entre direito civil e direito constitucional atravessou, nos últimos dois séculos, três fases distintas. $\mathrm{Na}$ primeira, situada no início do constitucionalismo moderno, a Constituição era vista como uma carta política que servia de referência para as relações entre Estado e cidadão, enquanto o Código Civil era o documento jurídico que regia as relações entre particulares frequentemente sendo mencionado como a "Constituição do direito privado". A segunda fase, denominada pelo autor de "publicização do direito privado", deu-se ao longo do século XX, quando, com a percepção da desigualdade material entre os indivíduos, o direito civil inicia a superação do individualismo exacerbado, deixando de ser o reino absoluto da autonomia da vontade. Em nome da solidariedade social e da função social de instituições como a propriedade e o contrato, o Estado começa a interferir nas relações entre particulares, com a introdução de normas de ordem pública (o chamado dirigismo contratual). Por fim, a terceira fase é marcada pela passagem da Constituição para o centro do sistema jurídico. É nesse ambiente que ocorre a virada axiológica do direito civil, com a vinda de normas deste para a Constituição e a ida desta para a interpretação do direito civil. Um novo conjunto de valores e princípios passa a ser imposto, tais como: a função social da propriedade 
e dos contratos, a proteção do consumidor, a boa-fé objetiva, o equilíbrio contratual, entre tantos outros de evidente ancoragem social.

Com efeito, a constitucionalização do direito civil se afigurou como consequência inevitável da passagem do Estado liberal para o Estado social, sendo um fenômeno doutrinário que tomou corpo principalmente a partir da última década do século $X X$, em razão das preocupações de juristas com a revitalização desse ramo do direito e sua adequação aos valores da Constituição de 1988, que consagra o Estado social, tendo como objetivos "constituir uma sociedade livre, justa e solidária", com redução das desigualdades sociais. $E$, desse modo, a ordem jurídica infraconstitucional também deve concretizar a organização social e econômica eleita pela Constituição, não podendo o direito civil permanecer ancorado no modelo liberal do século XIX (LÔBO, 2008). Segundo Barroso (2008), ao longo do século XX, o Código Civil de 1916 já vinha perdendo influência, na medida em que inúmeras leis específicas foram editadas, como em relação a locações, divórcio, alimentos e consumidor.

Tepedino (2003, p. 119) ensina que a constitucionalização do direito civil significa que as "relações patrimoniais deixam de ter justificativa e legitimidade em si mesmas, devendo ser funcionalizadas a interesses existenciais e sociais, previstos pela própria Constituição".

A influência desse fenômeno não deixou de ser sentida em diversos ramos do direito privado, a exemplo do direito de autor, consoante será visto a seguir.

1.1 O direito de autor e o direito à cultura dentro de uma perspectiva constitucional

AConstituição Federal de 1988 preconiza, no artigo $5^{\circ}$, inciso XXVII, que pertence aos autores o direito exclusivo de utilização, publicação ou reprodução de suas obras; direito transmissível aos herdeiros pelo tempo fixado em lei (BRASIL, 1988). No plano infraconstitucional, a Lei $n^{\circ} 9.610 / 1998$ é a atual normativa sobre o tema. 
Para Bittar (1994), o direito de autor é o ramo do direito privado que regula as relações jurídicas da criação e utilização econômica de obras intelectuais compreendidas na literatura, nas artes e nas ciências. Na mesma senda, segue Ascensão (1997), para quem o direito de autor tem por objetivo a tutela da criação literária, científica e artística, outorgando-se um direito exclusivo ao autor, que passa a ser o titular da exploração econômica da obra.

Lemos (2011) esclarece que o direito de autor é dotado de uma natureza sui generis, na medida em que seu conteúdo se desdobra em dois direitos autônomos. O primeiro diz respeito aos direitos patrimoniais, que consistem na exploração econômica da obra, elencados no artigo 29 da Lei de Direitos Autorais. Eles perduram por toda a vida do autor e são transferidos aos herdeiros pelo prazo de mais 70 (setenta) anos, contados a partir do dia $1^{\circ}$ de janeiro subsequente ao seu falecimento, período após o qual a obra cai em domínio público. O segundo referese aos direitos morais, relacionados ao reconhecimento da paternidade da obra. São irrenunciáveis, inalienáveis e imprescritíveis, indicados no artigo 24 da LDA.

Ainserção, no texto constitucional, da proteção aos direitos de autor demonstra a importância que os bens de natureza imaterial possuem para o desenvolvimento intelectual e econômico de um Estado. O direito de autor tem se tornado cada vez menos uma questão de regulação de direitos privados, passando a ser inserido no texto constitucional, e cada vez mais uma questão que afeta interesses diversos da sociedade (SANTOS, 2006).

O interesse social no tema se sobressai porque os direitos de autor também estão relacionados com a preservação do patrimônio cultural de um país, o qual está ligado à criação e manutenção de políticas públicas que fomentem a diversidade cultural, na medida em que esse direito serve como instrumento legal de sustentação de tais políticas. O bem intelectual não se resume, portanto, a um produto de indústrias criativas a ser consumido pelas massas como qualquer outro bem de consumo. A 
obra reflete os valores e significados culturais que extrapolam a relação privada de consumo (WACHOWICZ, 2010b).

Do mesmo modo que o direito de autor, o direito à cultura também encontra resguardo na Carta Magna, na medida em que o artigo 215 dispõe que "o Estado garantirá a todos o pleno exercício dos direitos culturais e acesso às fontes da cultura nacional, e apoiará e incentivará a valorização e a difusão das manifestações culturais". Por sua vez, no artigo 216 , parágrafo $3^{\circ}$, está disposto que "a lei estabelecerá incentivos para a produção e o conhecimento de bens e valores culturais" (BRASIL, 1988). Observa-se, portanto, que o ordenamento jurídico brasileiro confere especial atenção à cultura, existindo um compromisso do Estado em preservar e difundir aspectos relativos ao patrimônio cultural brasileiro.

E esse é um tema diretamente relacionado com a identidade de um povo, o que autoriza afirmar, a partir de Ascensão (2011a), que o acesso à cultura deve ser considerado objeto de direito fundamental. Discorrendo sobre o tema, Silva (2009) vai mais além e sustenta que as normas que versam sobre direitos culturais devem ser compreendidas dentro do complexo marco dos direitos humanos, na medida em que estão positivadas na Declaração Universal dos Direitos Humanos. Para demonstrar a importância do tema, Silva (2009, p. 838) afirma que a Constituição de 1988

[...], deu relevante importância à cultura, tomado esse termo em sentido abrangente da formação educacional do povo, expressões criadoras da pessoa e das projeções do espírito humano materializadas em suportes expressivos, portadores de referências à identidade, à ação, à memória dos diferentes grupos formadores da sociedade brasileira, que se exprimem por vários dos seus artigos $\left(5^{\circ}, \mathrm{IX}, 23, \mathrm{III}\right.$ a V, 24, VII a IX, 30, IX, e 205 a 217), formando aquilo que se denomina ordem constitucional da cultura, ou constituição cultural, constituída pelo conjunto de normas que contêm referências culturais e disposições consubstanciadoras dos direitos sociais relativos à educação e à cultura. 
No âmbito internacional, o Brasil também é signatário do Pacto Internacional Sobre Direitos Econômicos, Sociais e Culturais (International Covenant on Economic, Social and Cultural Rights), adotado pela Organização das Nações Unidas (ONU) em 1966 e incorporado ao ordenamento brasileiro pelo Decreto $n^{\circ} 591$, de 6 de julho de 1992. Pelo Pacto, os países signatários reconhecem a todos o "direito de participar da vida cultural", comprometem-se a "respeitar a liberdade indispensável à pesquisa científica e às atividades criadoras" e a adotar medidas necessárias para "assegurar a manutenção, o desenvolvimento e a difusão da ciência e da cultura" (ONU, 1966). O Brasil também ratificou, por meio do Decreto $n^{\circ} 6.177$, de $1^{\circ}$ de agosto de 2007, a Convenção sobre a Proteção e Promoção da Diversidade das Expressões Culturais (Convention on the Protection and Promotion of the Diversity of Cultural Expressions), aprovada em 2005 pela Organização das Nações Unidas para a Educação, a Ciência e a Cultura (UNESCO).

Segundo Cunha Filho (2011), os direitos culturais - os quais pressupõem a especificação de categorias de direitos relacionados à cultura, compreendida com base em núcleos concretos formadores de sua substância, como as artes, a memória coletiva e o fluxo dos saberes - vêm acompanhados de respectivos deveres culturais e de responsabilidade tanto do Estado, que tem múltiplos papéis na missão de garantidor do pleno exercício dos direitos culturais, quanto de outros atores sociais.

Nesse campo dos direitos culturais, existe uma distinção entre o que a doutrina entende por direito à cultura e direito da cultura. Conforme a lição de Cunha Filho (2011), direito à cultura remete aos aspectos genéricos e abstratos da convivência humana, correspondendo à prerrogativa de participar na vida cultural da comunidade. Já o direito da cultura refere-se ao direito que rege as relações específicas e tangíveis, com base em elementos do universo da cultura, levando à regulamentação dos serviços públicos culturais.

Essa distinção se mostra pertinente à compreensão do tema, pois o tratamento jurídico do direito de autor suscita o conflito entre o interesse 
individual de quem concebe intelectualmente a obra e reclama proteção constitucional e, por outro lado, o direito de todos terem acesso à cultura, na medida em que as normas constitucionais obrigam a atuação estatal para promover o acesso aos bens culturais. Tal tensão ocorre porque o direito de autor tradicionalmente esteve pautado na ideia de que quem cria uma obra deve receber o retorno sobre seu esforço e dedicação. Todavia, existe também interesse em que esse conhecimento produzido seja divulgado e atinja o maior número de pessoas. Assim, existe uma colisão entre o interesse social, que defende a liberdade de acesso, e a esfera comercial, que se norteia pelo interesse patrimonial e busca o controle sobre o acesso e a utilização dessa produção (ROVER; WINTER, 2002).

Tal situação, típica de sociedades complexas, evidencia que o direito de autor não pode ser compreendido de maneira estanque, devendo ser feita uma interpretação concomitante com os princípios de acesso à cultura, à educação e ao conhecimento. É nesse contexto que deve ser entendido o conflito entre o direito de autor e o direito à cultura.

Assim, observa-se que a visão clássica do direito de autor - de exclusividade absoluta do criador sobre a obra - não encontra mais respaldo. Com a reconfiguração do direito civil, o direito de autor, assim como outros institutos de direito privado, tais como a propriedade e o contrato, num contexto civil-constitucional, passou por transformações que demonstraram a importância de se estar em harmonia com os interesses sociais e os outros direitos fundamentais.

De tal modo, embora o ordenamento jurídico confira proteção ao direito de autor, essa proteção não pode ser absoluta. Ela deve ser balizada, a fim de tutelar o exercício de outros direitos fundamentais garantidos na Constituição de 1988. Existe a necessidade de se proteger as criações intelectuais, como forma de reconhecer e remunerar o criador pela sua obra, inclusive incentivando-o a novas criações. Todavia, esse direito deve tolerar restrições sempre que servir de empecilho à consecução de outros direitos, como o de acesso à cultura. 
É nesse contexto que se mostra essencial a ideia de função social dos institutos jurídicos privados. Ela determina que o direito de propriedade sobre um bem seja limitado e condicionado, de maneira a equilibrar o interesse individual do proprietário e o interesse público. É, segundo Reis e Pires (2011a), uma mudança de paradigma, do individualismo para a socialização, tendo por objetivo a conscientização do direcionamento dos institutos privados para uma visão mais social e fraterna nas relações particulares.

No que tange ao direito de autor, com a evolução no estudo sobre o tema, desenvolveu-se a ideia de que ele também está sujeito a uma vinculação social, a qual impõe balizas à titularidade absoluta e exclusiva do autor sobre a obra. Para Carboni (2008), o direito de autor tem como função social a promoção do desenvolvimento econômico, cultural e tecnológico, mediante a concessão de um direito exclusivo para a exploração de determinadas obras por certo prazo, após o qual a obra cai em domínio público e pode ser livremente utilizada. Assim, a função social do direito de autor funciona como limitadora do direito patrimonial individual, na medida em que o interesse particular na obra não pode ser absoluto.

Kretschmann (2011) pondera que a função social é inerente à propriedade intelectual, principalmente porque se trata de uma propriedade sobre bens cuja natureza promove o conhecimento, a educação e a difusão cultural. Embora a proteção ao autor deva ser destacada como promotora da dignidade humana, o direito de autor não pode ser tomado isoladamente, sem correspondência à esfera pública, como se o autor fosse uma ilha e não precisasse de ninguém. Conclui a autora (2011, p. 228): "o próprio autor, salvo raríssimas exceções [...], deseja ver sua obra difundida, revisitada, recriada, e a partir disso, desenvolver novas relações com o próprio ser que cresce na obra ao ser trabalhada pelo público".

É nesse sentido, em consonância com a irradiação dos valores constitucionais sobre os institutos clássicos de direito privado, que existem as limitações aos direitos de autor - situações previstas na LDA 
que não constituem ofensa a tais direitos. São casos específicos em que as obras protegidas podem ser utilizadas, mesmo sem autorização do detentor dos direitos, buscando-se garantir o equilíbrio entre os interesses deste e a manutenção do acesso ao conhecimento e às fontes de cultura (LEMOS, 2011).

Para Carboni (2008), as limitações estabelecidas na LDA são a mais evidente manifestação da função social, na medida em que determinam o que não pode ser objeto de proteção legal por prejudicar o interesse público.

Leciona Ascensão (2006) que as limitações sempre fizeram parte das convenções internacionais sobre o tema. Como exemplo, o doutrinador menciona que, na União Europeia, o ponto mais alto que trata do tema é a Diretiva 2001/29, de 22 de maio de 2001, a qual, ao regular aspectos do direito de autor na sociedade informacional, dispõe sobre os limites ao direito patrimonial do detentor da obra. $\mathrm{Na}$ LDA brasileira, as limitações estão previstas no Capítulo IV, artigos 46, 47 e $48^{1}$. De modo geral, a doutrina interpreta-as como sendo taxativas, sendo inadmissível qualquer outra exceção não expressa (LEMOS, 2011).

Lemos (2011) defende que o acesso cada vez maior a bens culturais é de interesse da sociedade, na medida em que isso estimula o processo plural e colaborativo de produção cultural. Para o autor, não se pode ignorar o fato de que grandes obras da humanidade, no plano cultural, artístico ou científico, foram fruto de uma longa gestação à base de enriquecimento intelectual, evidenciando a importância do acesso às obras intelectuais. Um exemplo bastante elucidativo é o caso da Disney, que criou diversos filmes com base em obras anteriores. É de

\footnotetext{
Alguns exemplos de limitações ao direito de autor previstas no artigo 46 da LDA são: a) a informação em si, por meio da reprodução de notícias (inciso I, a), o que garante que a sociedade tenha direito à livre circulação de notícias; b) a reprodução na imprensa de discursos pronunciados em reuniões públicas (inciso I, b); c) a reprodução de obras, sem fins comerciais, feita mediante o sistema Braille, para uso exclusivo de deficientes visuais (inciso I, d); d) a reprodução de pequenos trechos, para uso do copista, desde que sem intuito de lucro (inciso II); e) a citação de passagens de qualquer obra para fins de estudo, crítica ou polêmica (inciso III).
} 
se pensar que, caso as obras das quais a Disney se utilizou estivessem acobertadas por direitos de autor, muitas de suas criações não teriam existido.

Verifica-se, portanto, que as limitações ao direito de autor vêm favorecer e estimular a difusão cultural. Apesar dessa constatação, as limitações expressas na LDA tornam essa legislação uma das mais restritivas do mundo, fazendo-a merecedora de críticas pelo fato de ainda predominar no Brasil o viés patrimonial-individualista, que historicamente permeou o direito privado, destacando-se o excesso de proteção dos bens intelectuais como forma de garantia da retribuição financeira do autor (REIS; PIRES, 2011a).

Ascensão (2011a) exemplifica esse problema ao mencionar que o artigo 46, inciso II, da LDA, que faz referência ao uso privado da obra, é totalmente restritivo, pois somente permite a cópia desde que feita pelo próprio copista, de pequenos trechos, num só exemplar, para uso privado e sem intuito de lucro.

No mesmo sentido, Lemos (2011) aponta que atos que representam a efetivação da função social do direito de autor não são permitidos pela lei, tais como: cópia para preservação da obra ou para fins didáticos, inclusive por meio de digitalização; cópia privada visando preservar obras fora de circulação comercial; exibição de filmes em salas de aula para fins educacionais; remixes. E conclui que com uma norma que proíbe a cópia de obras para uso educacional ou científico num país cujo nível de renda da população e preço dos livros são incompatíveis, o acesso a recursos educacionais - elemento fundamental para o desenvolvimento de mão de obra qualificada - se mostra altamente restringido.

Por tudo isso, a atual LDA, ainda que relativize o direito exclusivo do autor, ainda serve de entrave à funcionalização desse direito, o que ocorre especialmente em virtude de seu caráter essencialmente protecionista (REIS; PIRES, 2011a).

Em suma, observa-se que as limitações especificadas pela LDA não se coadunam mais com a realidade atual, especialmente em razão 
das novas práticas sociais engendradas pelo uso das tecnologias da informação e comunicação, conforme será tratado no tópico a seguir.

\section{O conflito entre direito de autor e direito à cultura na sociedade informacional}

As transformações ocasionadas pela sociedade informacional ${ }^{2}$, com a ascensão e utilização massiva da internet, que propiciaram o incremento na capacidade e velocidade de comunicação, facilitando o acesso e transmissão de informações, impactaram de forma significativa em diversos campos do direito.

Marques e Martins (2006) explanam que, na sociedade informacional, a informação é substituída pela energia como fonte de progresso, tornando-se o principal recurso econômico e elemento determinante da economia e geração de emprego. Para os autores, o direito não tem como ser indiferente à evolução resultante das novas tecnologias, sendo múltiplos e complexos os problemas jurídicos suscitados nessa realidade.

De acordo com Ascensão (2011), a revolução informática trouxe para primeiro plano a questão do acesso aos conteúdos existentes na internet, sobretudo se considerado que a cultura cada vez mais se baseia em produtos com suporte virtual ou, ao menos, digitalizáveis, tornando a internet repositório desse acervo cultural mundial.

2 No presente trabalho, utiliza-se o conceito de sociedade informacional proposto por Castells (1999, p. 64-65). Conforme o autor: "O termo sociedade da informação enfatiza o papel da informação na sociedade. Mas afirmo que informação, em seu sentido mais amplo, por exemplo, como comunicação de conhecimentos, foi crucial a todas as sociedades [...]. Minha terminologia tenta estabelecer um paralelo com a distinção entre indústria e industrial. Uma sociedade industrial (conceito comum na tradição sociológica) não é apenas uma sociedade em que há indústrias, mas uma sociedade em que as formas sociais e tecnológicas de organização industrial permeiam todas as esferas de atividade, começando com as atividades predominantes localizadas no sistema econômico e na tecnologia militar e alcançado os objetos e hábitos da vida cotidiana. Meu emprego dos termos 'sociedade informacional' e 'economia informacional' tenta uma caracterização mais precisa das transformações atuais, além da sensata observação de que a informação e os conhecimentos são importantes para nossas sociedades". 
Uma das áreas que mais tem proporcionado debates é a do direito de autor. Por um lado, a internet possibilitou uma maior difusão das criações intelectuais, ampliando o acesso aos bens culturais. Por outro, ela acentuou o conflito entre direito de autor e direito à cultura, na medida em que muito do que está disponibilizado livremente na rede mundial de computadores hoje é protegido pelo direito de autor.

Consoante Reis e Pires (2011b), a internet ofereceu novas formas de criação, modificação e acesso aos bens culturais, provocando uma guinada no modelo comportamental da sociedade, que passou a utilizar a rede para acessar obras intelectuais, com fins educacionais ou culturais, de maneira cada vez mais ampla. Contudo, essas novas formas de acesso também geraram um conflito entre os interesses do autor - que, em regra, não obtém retribuição financeira pelo livre acesso de suas obras feito pelos usuários da internet - e o interesse da sociedade no acesso à informação, à cultura e à educação.

Observa-se, portanto, que a proteção tradicional ao direito de autor (elaborada para tutelar de forma precípua a obra corporificada no papel, no $C D$ etc.) encontra-se em crise frente às inovações tecnológicas que possibilitam a desmaterialização da obra, com a consequente ampliação de sua circulação.

Para Wachowicz (2011), há um paradoxo no fato de que a sociedade informacional se estrutura a partir do primado da liberdade de informação em favor da disseminação do conhecimento e da cultura. Afinal, apenas pode haver uma sociedade informacional se existir garantia de liberdade de acesso à informação. Por outro lado, somente se justifica o sistema de tutela jurídica dos bens intelectuais caso se conceda um direito exclusivo ao autor. Assim, tem-se um conflito de direitos, na medida em que boa parte do conteúdo disponível na rede mundial de computadores é protegida por leis de direitos de autor.

Embora boa parte das atitudes de usuários da internet configure violação de direitos de autor, é patente que essa divulgação massiva de bens culturais contribui para cumprir a função social do direito de autor, ao propiciar de maneira ampla e facilitada o acesso à informação, à 
educação e à cultura, em consonância com os preceitos constitucionais sobre o tema. Desse modo, verifica-se que a sociedade informacional acentuou um conflito que já existia, embora em menor escala: o interesse privado do titular do direito sobre a obra (o autor e, às vezes, também o editor) e o interesse público da coletividade em ver facilitado o acesso a bens culturais.

Assim, diante desse impasse, surge o desafio de estabelecer um equilíbrio entre o interesse do criador e o interesse da sociedade no acesso à cultura, de maneira a primar-se pela função social do direito de autor. É nesse sentido que esse conflito deve ser trabalhado, a fim de buscar o balanceamento entre dois interesses antagônicos.

\subsection{As potencialidades da internet para a difusão cultural: necessidades de adaptação legal}

O direito de autor costumava ser visto sempre pela relação particular entre autor da obra e público consumidor. Contudo, dentro de uma perspectiva constitucional, perpassando todas as relações privadas, percebe-se que o direito de autor não pode mais ser entendido estritamente por esse viés privado, pois ele tem um nítido papel em relação à promoção do acesso à cultura, à informação e à educação. $\mathrm{E}$ dentro desse contexto, as potencialidades demonstradas pela internet para contribuir com o direito constitucionalmente previsto de acesso à cultura não podem ser desconsideradas.

Reis e Pires (2011a) referem que a socialização do conhecimento constitui uma das principais bases da inovação e construção de outros conhecimentos. Assim sendo, do ponto de vista social, as ferramentas que a internet proporciona tornam-se extremamente valiosas para o compartilhamento de bens intelectuais, os quais se constituem em fontes de conhecimento e o acesso a eles é requisito essencial para a promoção do desenvolvimento cultural, econômico e tecnológico de uma sociedade.

Lévy (1999, p. 205) elucida com propriedade esse confronto entre o direito de autor e os interesses econômicos que cercam a questão, 
em contraponto à possibilidade sem precedentes oferecida pela internet para a produção e difusão do conhecimento:

O ciberespaço constitui um imenso campo de batalhas para os industriais da comunicação e dos programas. Mas a guerra que opõe algumas grandes forças econômicas não deve mascarar a outra que coloca em choque uma visão puramente consumista do ciberespaço, a dos industriais e vendedores [...] e uma outra visão, a do movimento social que propaga a cibercultura, inspirado pelo desenvolvimento das trocas de saberes, das novas formas de cooperação e da criação coletiva nos mundos virtuais.

É sabido que boa parte das atitudes tomadas pelos usuários da internet desafia as regras clássicas de direito de autor. Por exemplo, no rol das limitações aos direitos de autor não se encontra a permissão para realizar cópia integral de obra legitimamente adquirida. Em outras palavras, a lei não autoriza que determinada pessoa que tenha adquirido de maneira legítima um CD possa copiar o seu conteúdo para um tocador de MP3. Outro tema bastante polêmico e não contemplado na LDA é o compartilhamento de arquivos/redes peer-to-peer (P2P). Lemos (2011) ensina que não existe obstáculo legal para a existência das redes P2P e muitas delas são usadas para fins legais. Contudo, a popularização do uso dessas redes para troca de arquivos contendo obras protegidas levou a indústria do entretenimento a mover diversas ações pleiteando o fechamento dessas plataformas, alegando perdas financeiras.

Assim, Palfrey e Gasser (2011) ensinam que a "epidemia do compartilhamento de arquivos" tem obrigado a sociedade a repensar o sistema de direitos de autor, o qual atualmente está em descompasso com as normas sociais dominantes dos internautas. A maioria dos esforços feitos para "educar" os internautas em suas atitudes violadoras de direitos - a exemplo de campanhas financiadas pelos grupos da indústria detentores de direitos autorais - conseguiu poucos resultados. Por outro lado, é necessário que a busca pelo fim da pirataria não signifique o fim das novas formas de criatividade propiciadas pela internet. 
Portanto, a questão deve ser analisada mais a fundo, não somente com campanhas de conscientização dos consumidores (as quais muitas vezes equiparam um download de uma música da internet ao furto de um carro) e políticas repressivas. Na questão do acesso e compartilhamento de arquivos digitais protegidos pela legislação autoral, Lemos (2011) destaca que duas grandes questões incentivadoras dessa prática são: a) o alto preço dos produtos comercializados no Brasil; e b) a distribuição desigual ou ineficiente de bens culturais. Desse modo, pondera que o Brasil deveria buscar a efetivação de políticas públicas que promovam a redução de obstáculos ao consumo legal de bens culturais (o que implica pensar em preços, tributação, licenciamento e distribuição), em vez de investir em medidas simplesmente moralizantes ou repressivas.

No mesmo sentido é a posição de Kretschmann (2011), para quem, se as infrações ao direito de autor são praticadas com tanta naturalidade, é necessário investigar a causa disso. A autora pondera que, no Brasil, o preço de livros e CDs, por exemplo, é impraticável para boa parte da população e, no caso dos que podem pagar pelos bens culturais, é feita uma seleção criteriosa do que será adquirido, pois o preço dos produtos faz com que o consumidor se sinta "roubado" e acabe por adquirir a obra de maneira clandestina.

Palfrey e Gasser (2011), tratando do tema, referem que os jovens mais criativos estão interagindo com as notícias, o entretenimento e as informações de formas inimagináveis há alguns anos. Não são consumidores passivos do que a mídia apresenta, e sim participantes ativos na construção da cultura. Os autores citam como exemplo o remix, em que os arquivos digitais são combinados para criar um novo arquivo, assim como os novos modelos de negócios criados (Napster, Facebook, Youtube) para distribuição de mídia digital. No entanto, os autores ponderam que boa parte dos internautas não tem (muita) consciência de que, com suas atitudes, como assistir a filmes/programas de televisão ou ouvir músicas utilizando programas para realizar o download e acessar esse conteúdo gratuitamente, ela está constantemente violando leis de direitos de autor. 
Lemos (2011) refere ser imperioso que se façam adaptações na atual LDA para adequá-la à sociedade informacional, à crescente digitalização de conteúdos e às atuais práticas sociais. Atitudes como copiar em um blog um texto encontrado na internet, buscar uma imagem na rede e inseri-la numa apresentação de Power Point, gravar no MP3 player o conteúdo de um CD e disponibilizar uma música numa rede de compartilhamento P2P podem ser consideradas legais por boa parte da sociedade, de tão corriqueiras que são. No entanto, de acordo com a lei, nenhuma dessas condutas é permitida. Por isso, Lemos (2011, p.73) alerta: "em um contexto em que grande parte da população age de forma contrária à lei, é preciso que haja um debate franco sobre o descompasso entre o direito e a sociedade".

Palfrey e Gasser (2011) destacam que a contínua violação a direitos de autor por parte dos internautas decorre, muitas vezes, devido à ausência de conhecimento acerca das leis que regulam a propriedade intelectual, afirmando que boa parte dos usuários da internet acredita que as formas de cópia privada e não comercial de obras protegidas por direitos de autor são, ou ao menos deveriam ser, permitidas. Já Souza e Castro (2011) mencionam que, embora parte da doutrina considere que o compartilhamento de arquivos via rede P2P configure violação a direitos de autor, existe uma parte significativa da sociedade que entende que a utilização desses mecanismos, sem finalidade lucrativa, representa a mera circulação livre de informação no meio social, o que não poderia ser controlado, cobrado ou taxado.

Desse modo, tem-se verificado que a atual legislação brasileira se afigura insuficiente frente às transformações propiciadas pela sociedade informacional. Consoante Palfrey e Gasser (2011, p. 167), "a lei dos direitos autorais no ambiente tecnológico vertiginoso de hoje tem um impacto negativo sobre a inovação - inovação que a lei da propriedade intelectual deve servir em primeiro lugar".

As atuais limitações da LDA pátria não se coadunam mais com a realidade atual. Se é verdadeiro que a internet auxilia no cumprimento da função social do direito de autor, na medida em que facilita a circulação 
da informação, essa facilidade vem muitas vezes acompanhada de violação ao direito patrimonial do detentor da obra. Para citar apenas um exemplo, veja-se que a digitalização de conteúdos protegidos, embora viole a LDA, cria um enorme potencial social de acesso ao conhecimento, à educação e ao intercâmbio cultural.

No entanto, em contraponto a uma solução equilibrada, Wachowicz (2011) esclarece que a tendência internacional das legislações relativas à propriedade intelectual é de recrudescimento da tutela dos direitos do autor, a fim de proteger interesses econômicos. Sobre isso, Kretschmann (2011) adverte que essas mudanças, tendentes a endurecer ainda mais o direito de autor e justificadas geralmente como sendo uma garantia ao criador de aproveitamento do seu trabalho, servem muito mais a interesses da indústria cultural.

Um exemplo de estratégia utilizada para controlar o acesso aos bens intelectuais são as medidas de restrição tecnológicas inseridas pela indústria em arquivos que contêm obras comercializadas em formato digital. Tais restrições são severamente criticadas, pois retiram do consumidor o direito de decidir o que fazer com os conteúdos digitais legitimamente adquiridos (LEMOS, 2011).

Segundo Carboni (2008), interesses comerciais movem todo um processo de alargamento do objeto de proteção do direito de autor e de prolongamento do prazo de proteção. Nos últimos anos, com as transformações sociais decorrentes da tecnologia digital, o direito de autor passou de mecanismo de estímulo à produção intelectual a ferramenta de uma poderosa indústria de bens intelectuais que se apropria da informação enquanto mercadoria, transformando-se em obstáculo para formas mais dinâmicas de criação e circulação das obras.

Na seara internacional, é bastante fácil perceber uma tendência de endurecimento da legislação. Na França, foi aprovada em 2009 a Lei Hadopi. Segundo Solagna, Souza e Leal (2011, p. 73), o diploma "enfatiza o caráter ameaçador e desestabilizador desse mesmo meio [a internet], o qual é demonstrado através de cifras de redução de investimento e contratos na indústria cultural provocadas pela 'cultura 
da pirataria'". Entre as previsões da lei, encontra-se a responsabilidade dos provedores de acesso em suspender as contas de usuários de plataformas de compartilhamento de arquivos protegidos se, após o envio de três avisos comunicando a infração, esta não cessar (SOLAGNA; SOUZA; LEAL, 2011). A Ministra da Cultura Francesa chegou a considerar o sistema da lei ineficaz, mas, apesar das pressões - inclusive internacionais -, a lei segue em vigor (DIAS, 2012).

Nos Estados Unidos, houve uma polêmica discussão, com contornos mundiais, acerca de dois projetos de lei intitulados "Stop Online Piracy Act"3" (SOPA) e "Preventing Real Online Threats to Economic Creativity and Theft of Intellectual Property Act" (PIPA). Esses projetos, que tinham o intuito de proteger a propriedade intelectual atualizando a legislação do país, causaram uma acirrada tensão entre a indústria e os defensores de uma internet livre. Devido à pressão internacional, os projetos foram arquivados (DIAS, 2012).

Para Wachowicz (2010a), a interatividade e o compartilhamento de arquivos, quando feitos sem finalidade lucrativa, não enfraquecem os direitos de autor, e sim possibilitam o acesso e seguem divulgando a criação de determinada pessoa. Ou seja, não retiram a titularidade do bem intelectual, apenas não conferem necessariamente um valor econômico de exploração restrita. Uma lei autoral menos restritiva possibilitaria não só maior acesso do público às obras como também contribuiria para a divulgação de artistas que, em razão da ausência de um interlocutor, permanecem anônimos e desconhecidos.

Em uma pesquisa divulgada em abril de 2011 pela Consumers International, organização que reúne entidades de proteção ao consumidor de todo o mundo, a legislação de direitos autorais do Brasil foi classificada como a $4^{a}$ pior dentre 24 países analisados, ficando na frente apenas de Reino Unido, Chile e Tailândia. No Brasil, os dados foram levantados pelo Instituto Brasileiro de Defesa do Consumidor

Lei de combate à pirataria on-line (tradução nossa)

4 Lei de prevenção contra roubos e ameaças virtuais à propriedade intelectual (tradução nossa) 
(IDEC). De acordo com o estudo, chamado de "IP Watchlist", as leis brasileiras são tão rígidas que prejudicam o acesso à cultura e o uso educacional de obras protegidas por direitos autorais.

Portanto, fica evidente que o direito de autor, do modo como é atualmente tratado na lei, torna-se um óbice à difusão dos bens culturais, afinal, poucas são as atitudes tomadas pelos internautas que estão em plena consonância com a regulação sobre o tema.

Configura-se necessário, portanto, uma ampliação das limitações do direito de autor, buscando-se uma adequação ao contexto da sociedade informacional, para assegurar a efetividade da função social do autor, uma vez que as atuais exceções mostram-se insuficientes para a busca do equilíbrio entre direitos, servindo de empecilho à difusão cultural. Segundo Reis e Pires (2011b, p. 322), "por meio de uma interpretação literal do regime atual de direitos autorais, qualquer usuário de internet pode ser transformado em um potencial infrator de direitos ou ainda, de maneira mais drástica, em um potencial criminoso".

É nesse sentido que Wachowicz (2010b) alerta que o direito de autor não pode ser tratado como um "estado de exceção" para fundamentar posições extremistas, como as que são propagadas nas campanhas antipirataria. Nessas campanhas, grandes conglomerados de mídia buscam incutir o medo em pessoas comuns, induzindo o entendimento de que, pelo simples fato de utilizarem recursos tecnológicos disponíveis em aparelhos eletrônicos, estariam se transformando em falsificadores, piratas e criminosos.

É por isso que qualquer mudança na legislação, embora urgente e necessária, deve ser pensada com cuidado, principalmente no que toca às limitações, pois são elas que vão determinar o quão restritiva será a lei e o quão adaptada estará ao ambiente digital.

Nesse contexto de insatisfação com a atual normativa, o Ministério da Cultura deu início a um debate acerca da revisão da lei, buscando atualizar as disposições legais sobre o tema. O texto da proposta de mudança da lei passou por duas consultas públicas, em 2010 e 2011. 
Após a segunda consulta, foi redigida uma nova minuta do anteprojeto de lei de modernização da LDA (BRASIL, 2012). Apesar da relevância do assunto e da necessidade de uma lei adaptada à sociedade informacional, a última versão do anteprojeto não foi divulgada à sociedade e a discussão segue paralisada desde então ${ }^{5}$.

Essa proposta de revisão da LDA vem inserida no contexto de transformações pelas quais a sociedade passou nos últimos anos, as quais se devem, em essência, ao surgimento da internet. $O$ conflito entre o interesse público de acesso à cultura e o interesse patrimonial do autor revelou-se ainda mais marcante com as possibilidades trazidas pela sociedade informacional, acentuando o embate entre os dois direitos e demonstrando a necessidade de aproximar a legislação ao tema do seu caráter social. Principalmente no sentido de buscar uma conciliação desse conflito, pois, consoante declara Ascensão (2011a), devem ser buscadas vias de conciliação, uma vez que o público não pode pretender a gratuidade geral de acesso, mas também inexiste uma soberania absoluta do autor.

\section{Considerações finais}

As discussões concernentes ao direito de autor e ao direito à cultura, intensificadas pela sociedade informacional, evidenciam o abismo existente entre a legislação vigente e a realidade social.

Nesse sentido, é necessária a permanente busca de um equilíbrio entre interesses tão diversos quanto os dos criadores, do público e das organizações empresariais. Os poderes conferidos aos titulares de direito de autor devem ser substancialmente limitados em relação à normativa atual, que ainda trata o direito de autor como absoluto e entende que as restrições a ele devem ser as menores possíveis. Esse

Em contato via e-mail, diretamente com o Ministério da Cultura, foi informado que "A Diretoria de Direitos Intelectuais - DDI informa que o Anteprojeto que revisa a Lei de Direitos Autorais está em fase final de elaboração para posterior envio à Casa Civil, onde será analisado. Portanto, ainda é um documento de trabalho interno do executivo." (BRASIL, 2013) 
viés patrimonial e individualista, contudo, não encontra mais respaldo no mundo contemporâneo, devendo o direito de autor ser sempre pensado em consonância com a Constituição Federal e a função social que lhe é inerente.

O ambiente digital permite, de uma maneira impensável há algum tempo, a ampliação do acesso a bens culturais, contribuindo com a promoção do desenvolvimento econômico, tecnológico e cultural como um todo, possibilitando a consecução de um direito de autor plenamente funcionalizado. Entretanto, como grande parte das atitudes tomadas por internautas configuram violação ao direito de autor, verifica-se a premente necessidade de adequação da normativa vigente à realidade digital, buscando-se a conciliação entre os interesses dos titulares dos direitos sobre a obra e os interesses do público que deseja ver facilitada a circulação das informações e ampliado o acesso à cultura, direito garantido constitucionalmente.

Além disso, deve ser levado em consideração que o abrandamento do direito exclusivo dos autores é de interesse de muitos criadores, que veem numa legislação mais flexível a possibilidade de, em conjunto com as facilidades propiciadas pela internet, divulgar suas obras sem a necessidade dos intermediadores que atuam nesse ramo. Com efeito, a internet abriu a possibilidade de artistas desconhecidos - que antes não teriam a possibilidade de levar seu trabalho a público amplo sem o auxílio de empresas intermediárias - divulgarem suas obras de maneira fácil, pouco onerosa e atingindo milhares de pessoas. Obviamente, deve ser uma prerrogativa do criador optar pelo meio de divulgação e comercialização que entender mais adequado - se quer disponibilizar suas criações por meio da indústria tradicional, por meio de vias alternativas propiciadas pela internet ou ainda por uma combinação dessas duas possibilidades -, não podendo a lei retirar essa faculdade do autor.

Como demonstrado ao longo do texto, a atual LDA encontrase em evidente descompasso com a realidade, motivo pelo qual a sua alteração - já em curso, capitaneada pelo Ministério da Cultura 
- mostra-se urgente. Somente com dispositivos mais adequados à sociedade informacional é que a legislação estará em consonância com todo o processo de constitucionalização do direito, contribuindo para o cumprimento da sua função social, de modo a assegurar o direito constitucionalmente garantido de acesso à cultura.

\section{Referências}

ASCENSÃO, José de Oliveira. Direito autoral. Rio de Janeiro: Renovar, 1997.

. Direito de autor e liberdade de criação. In: WACHOWICZ, Marcos (Org.). Propriedade intelectual e internet. Curitiba: Juruá, 2011b. v. II. p. 17-40.

. Direito fundamental de acesso à cultura e direito intelectual. In: SANTOS, Manoel J. Pereira dos (Coord.). Direito de autor e direitos fundamentais. São Paulo: Saraiva, 2011a. p. 9-44.

. A função social do direito autoral e as limitações legais. In: ADOLFO, Luiz Gonzaga Silva; WACHOWICZ, Marcos (Coord.). Direito da propriedade intelectual: estudos em homenagem ao Pe. Bruno Jorge Hammes. Curitiba: Juruá, 2006. p. 85-111.

BARROSO, Luís Roberto. A constitucionalização do direito e o direito civil. In: TEPEDINO, Gustavo (Org.). Direito civil contemporâneo: novos problemas à luz da legalidade constitucional. São Paulo: Atlas, 2008. p. 238-261.

- Curso de direito constitucional contemporâneo: os conceitos fundamentais e a construção do novo modelo. São Paulo: Saraiva, 2010.

BITTAR, Carlos Alberto. Direito de autor. Rio de Janeiro: Forense Universitária, 1994.

BRASIL. Constituição da República Federativa do Brasil: promulgada em 5 de outubro de 1988. São Paulo: Revista dos Tribunais, 2012. 
Lei $\mathrm{n}^{\circ} 9.610$ de 19 de fevereiro de 1998. Altera, atualiza e consolida a legislação sobre direitos autorais e dá outras providências. São Paulo: Revista dos Tribunais, 2012.

Ministério da Cultura. Direito autoral: anteprojeto seguiu para Casa Civil depois de incorporar contribuições da sociedade. 9 jan. 2012. Disponível em: <http://www.cultura.gov.br/site/2012/01/09/134950/>. Acesso em: 11 abr. 2013.

. Ministério da Cultura. Fale com a cultura [mensagem pessoal]. Mensagem recebida por: <leticiarue@gmail.com> em 27 mar. 2013.

CARBONI, Guilherme. Função social do direito de autor. Curitiba: Juruá, 2008.

CASTELLS, Manuel. A sociedade em rede: a era da informação: economia, sociedade e cultura. São Paulo: Paz e Terra, 1999. v. 1.

CONSUMERS INTERNATIONAL. IP Watchlist 2011. Disponível em: <http://www.consumersinternational.org/media/694498/ipwatchlist2011engrvsd.pdf>. Acesso em: 11 abr. 2013.

CUNHA FILHO, Francisco Humberto. Direitos culturais no Brasil. Revista Observatório Itaú Cultural, São Paulo, n. 11, p. 115-126, jan./ abr. 2011. p. 115-126.

DIAS, Tatiana de Mello. 2012 passou sem revoluções, mas a mudança vem aos poucos. O Estado de São Paulo, São Paulo, 30 de dez. 2012. Disponível em: <http://blogs.estadao.com.br/tatiana-dias/2012-passousem-revolucoes-mas-a-mudanca-vem-aos-poucos/>. Acesso em: 11 abr. 2013.

KRETSCHMANN, Ângela. O acesso à cultura e o monopólio de obras intelectuais: onde está o bem público? Para onde vai o direito autoral? In: WACHOWICZ, Marcos (Org.). Propriedade intelectual e internet. Curitiba: Juruá, 2011. v. II. p. 223-246.

LEMOS, Ronaldo et al. (Org.). Direitos autorais em reforma. Rio de Janeiro: FGV, 2011.

LÉVY, Pierre. Cibercultura. São Paulo: Ed. 34, 1999. 
LÔBO, Paulo.Constitucionalização do direito civil. Revista de Informação Legislativa, Brasília, DF, v. 36, n. 141, p. 99-109, jan./mar. 1999.

LÔBO, Paulo. A constitucionalização do direito civil brasileiro. In: TEPEDINO, Gustavo (Org.). Direito civil contemporâneo: novos problemas à luz da legalidade constitucional. São Paulo: Atlas, 2008. p.19-28.

MARQUES, Garcia; MARTINS, Lourenço. Direito da informática. Coimbra: Almedina, 2006.

ORGANIZAÇÃO DAS NAÇÕES UNIDAS. International covenant on economic, social and cultural rights. 1966. Disponível em: <http:// www.ohchr.org/EN/Professionallnterest/Pages/CESCR.aspx>. Acesso em: 11 abr. 2013.

ORGANIZAÇÃO DAS NAÇÕES UNIDAS PARA A EDUCAÇÃO, A CIENCIAE A CULTURA. Convention on the protection and promotion of the diversity of cultural expressions. 2005. Disponível em: <http://portal.unesco.org/en/ev.php-URL_ID=31038\&URL_DO=DO_ TOPIC\&URL_SECTION=201.html>. Acesso em: 11 abr. 2013.

PALFREY, John; GASSER, Urls. Nascidos na era digital. Porto Alegre: Artmed, 2011.

REIS, Jorge Renato dos; PIRES, Eduardo. Direito autoral e internet: uma análise sob a perspectiva do direito civil-constitucional. In: WACHOWICZ, Marcos (Org.). Propriedade intelectual e internet. Curitiba: Juruá, 2011b. v. II. p. 311-325.

- O direito de autor funcionalizado. In: SANTOS, Manoel J. Pereira dos (Coord.). Direito de autor e direitos fundamentais. São Paulo: Saraiva, 2011a. p. 199-225.

ROVER, Aires José; WINTER, Djônata. A revolução tecnológica digital e proteção da propriedade intelectual. In:WACHOWICZ, Marcos (Coord.). Propriedade intelectual e internet: uma perspectiva integrada à sociedade da informação. Curitiba: Juruá, 2002. p. 75-89. 
SANTOS, Manoel J. Pereira dos Santos. Princípios constitucionais e propriedade intelectual: o regime constitucional do direito autoral. In: ADOLFO, Luiz Gonzaga Silva; WACHOWICZ, Marcos (Coord.). Direito da propriedade intelectual: estudos em homenagem ao Pe. Bruno Jorge Hammes. Curitiba: Juruá, 2006. p. 11-31.

SILVA, José Afonso da. Curso de direito constitucional positivo. 32. ed. São Paulo: Malheiros, 2009.

SOLAGNA, Fabrício; SOUZA, Rebeca Hennemann Vergara de; LEAL, Ondina Fachel. Regime propriedade intelectual: controle, liberdade e conflitos na gestão de bens intangíveis no contexto digital. In: WACHOWICZ, Marcos (Org.). Propriedade intelectual e internet. Curitiba: Juruá, 2011. v. II. p. 59-90.

SOUZA, Allan Rocha de; CASTRO, Raul Murad. R. de. Arte, tecnologia e sociedade. In: WACHOWICZ, Marcos (Org.). Propriedade intelectual e internet. Curitiba: Juruá, 2011. v. II. p. 373-392.

TEPEDINO, Gustavo. A constitucionalização do direito civil: perspectivas interpretativas diante do novo código. In: NAVES, Bruno Torquato de Oliveira; FIUZA, César; FREIRE de SÁ, Maria de Fátima (Coord.). Direito civil: atualidades. Belo Horizonte: Del Rey, 2003. p. 115-130.

WACHOWICZ, Marcos. Direitos autorais e o domínio público da informação. In: SANTOS, Manoel J. Pereira dos (Coord.). Direito de autor e direitos fundamentais. São Paulo: Saraiva, 2011. p. 226-253.

. Por que rotular a revisão da lei de direitos autorais no Brasil? Grupo de estudos em direitos autorais e informação da Universidade Federal de Santa Catarina. Florianópolis, 2010b. Disponível em: <http:// www.direitoautoral.ufsc.br/gedai/2010/06/por-que-rotular-a-revisao-dalei-de-direitos-autorais-no-brasil/> . Acesso em: 11 abr. 2013.

. A revisão da lei brasileira de direitos autorais. In: WACHOWICZ, Marcos; SANTOS, Manoel Joaquim Pereira dos (Org). Estudos de direito de autor e a revisão da lei dos direitos autorais. Florianópolis: Fundação Boiteux, 2010a. p. 73-101. 
. Revolução tecnológica e propriedade intelectual. In: PIMENTA, Eduardo Salles (Coord.). Direitos autorais: estudos em homenagem a Otávio Afonso dos Santos. São Paulo: Revista dos Tribunais, 2007. p. 225-245.

Recebido em: 00/11/13

Aprovado em: 00/12/13 